\title{
In Vitro Release and Electrophysiological Effects In Situ of Homocysteic Acid, An Endogenous N-Methyl-(D)-aspartic Acid Agonist, in the Mammalian Striatum
}

\author{
Kim Quang Do, * Paul L. Herrling, † Peter Streit, " Waldemar A. Turski, ${ }^{\dagger+1}$ and Michel Cuenod* \\ *Brain Research Institute, University of Zurich, Zurich, Switzerland, and †Wander Research Institute, Bern, \\ Switzerland
}

\begin{abstract}
A potassium-induced, calcium-dependent release of endogenous homocysteic acid (HCA) from rat striatal slices was demonstrated. A precolumn derivatization high-performance liquid chromatography method was developed that allowed quantitative determination of sulfur-containing amino acids at the picomole level.
\end{abstract}

Intracellular recordings from cat caudate neurons during simultaneous microiontophoretic application of drugs and electrical stimulation of the corticocaudate pathway showed that (L)HCA evoked a depolarization pattern similar to that induced by $N$-methyl-(D)-aspartic acid (NMDA), and both these depolarizations could be selectively inhibited by a specific NMDA antagonist, (D)-2-amino-7-phosphonoheptanoic acid [(D)-AP-7]. A selective antagonism of (L)-HCA-induced depolarizations by (D)-AP-7 was confirmed in quantitative experiments with the frog hemisected spinal cord in vitro. Small quantities of iontophoretically applied (L)-HCA, but not of quisqualate, potentiated cortically evoked EPSPs in cat caudate neurons.

These observations suggest that ( $\mathrm{L}$ )-HCA might be a candidate as an NMDA-receptor-preferring endogenous transmitter in the caudate nucleus. One possible function for such transmitter systems could be the enhancement of EPSPs.

Since the first observation that homocysteic acid (HCA) excites toad spinal neurons (Curtis and Watkins, 1961), this sulfurcontaining amino acid has been confirmed by many authors as one of the most potent neuronal excitants in various parts of the CNS. It has, however, not been shown to be an endogenous substance in the mammalian brain or to be released from nervous tissue. In order to screen for released substances, a precolumn derivatization high-performance liquid chromatography method (HPLC) has been developed that allows quantitative determination of HCA at the picomolar level in biological material (Do et al., 1986). We report here on the depolarizationinduced release of endogenous HCA from rat brain slice with special emphasis on striatal tissue, the electrophysiological ef-

\footnotetext{
Received Sept. 30, 1985; revised Dec. 26, 1985; accepted Jan. 20, 1986.

We are grateful to Dr. J. C. Watkins for many very helpful discussions and the gift of reference amino acids. We thank Mr. A. Faeh, J. Kuenzli, Ch. Durtschi, Ms. M. Mattenberger, Ms. F. Meier, E. Schneider, and R. Emch for technical assistance and Dr. H. O. Kalkman for help with $\mathrm{p} A_{2}$ values. This investigation was supported by grants of the Swiss National Science Foundation (3.455.83 and 3.228.82) and the Dr. Eric Slack-Gyr-Foundation. The HPLC equipment was generously financed by the Sandoz-Foundation, the "Jubilaeumsstiftung der Schweizerischen Lebensversicherung- und Rentenanstalt," the "Geigy Jubilaeumsstiftung," and the "Hartmann-Mueller-Stiftung" for which we express our thanks.

Correspondence should be addressed to Dr. Kim Quang Do, Brain Research Institute, August Forel Strasse 1, CH-8029 Zurich, Switzerland.

${ }^{1}$ Present address: Department of Pharmacology, Medical School, Jaczewskiego 8, 20-090 Lublin, Poland.

Copyright (c) 1986 Society for Neuroscience $0270-6474 / 86 / 082226-09 \$ 02.00 / 0$
}

fects of microiontophoretically applied (L)-HCA on membrane potential and cortically evoked EPSPs in cat caudate neurons, and the pharmacological specificity of $(\mathrm{L})-\mathrm{HCA}$ in this structure.

\section{Materials and Methods \\ Materials \\ Release}

4- $N, N$-Dimethylamino-azobenzene-4'-isothiocyanate (DABITC) was obtained from Fluka (Buchs, $\mathrm{CH}$ ) and recrystallized in acetone (Merck, Darmstadt, FRG). All other solvents used were of commercial analytical grade from Merck or Fluka. The internal standard (D,L)-2-amino-7sulfonoheptanoic acid (AS-7) was a generous gift of Dr. J. C. Watkins. (L)-homocysteic acid [(L)-HCA], (L)-cysteine sulfinic acid [(L)-CSA], (L)cysteic acid [(L)-CA], and veratrine were purchased from Sigma (St. Louis, MO). The Bio-Rad assay kit was used for protein determination.

\section{Iontophoresis}

The following drugs were used in the iontophoretic experiments and cjectcd as anions (all $0.1 \mathrm{M}$, except as noted): (D,L)-2-amino-7-phosphonoheptanoic acid (AP-7; Wander, CH); (D)-AP-7 (kindly donated by J. C. Watkins); (L)-CSA (Sigma); (L)-HCA (Sigma); $N$-methyl-(D)aspartic acid, $0.2 \mathrm{M}$ (NMDA, Tocris Chemicals, Buckhurst Hill, UK) and quisqualic acid (QUIS, Sigma).

All drugs were dissolved in 100 or $200 \mu \mathrm{l}$ of $1 \mathrm{~N} \mathrm{NaOH}$ and made up to $1 \mathrm{ml}$ with distilled water. The $\mathrm{pH}$ was adjusted to 8-9 with $\mathrm{HCl}$. All solutions were kept at $-17^{\circ} \mathrm{C}$ between experiments.

\section{Frog hemisected spinal cord}

The compounds used in vitro were from the same commercial sources. After initial solubilization, they were diluted in Ringer's solution, $\mathrm{pH}$ 7.2 .

\section{Release}

The $\mathrm{K}^{+}$-induced release in rat brain slices was performed as described by Do et al. (1986). Briefly, slices of striatal tissue containing parts of caudate-putamen, globus pallidus, and nucleus accumbens were superfused at a flow rate of $1 \mathrm{ml} / \mathrm{min}$ with freshly oxygenated Earl's bicarbonatc buffered salt solution $\left(\mathrm{Na}^{+}, 134 \mathrm{~mm} ; \mathrm{K}^{+}, 5 \mathrm{~mm} ; \mathrm{Ca}^{2+}, 2 \mathrm{~mm}\right.$; $\mathrm{Mg}^{2+}, 1 \mathrm{~mm} ; \mathrm{Cl}^{-}, 137.75 \mathrm{~mm} ; \mathrm{HCO}^{3-}, 20 \mathrm{~mm} ; \mathrm{H}_{2} \mathrm{PO}_{4}^{-}, 1.25 \mathrm{~mm} ; \mathrm{SO}_{4}{ }^{2-}$, $1 \mathrm{~mm}$; (D)-glucose, $10 \mathrm{~mm}$; gassed with $5 \% \mathrm{CO}_{2} / 95 \% \mathrm{O}_{2}, \mathrm{pH} 7.2$ ) at $37^{\circ} \mathrm{C}$ ("resting condition"). The eluate was collected as 5 min fractions. The slices were depolarized for a period of $4 \mathrm{~min}$ by raising the $\mathrm{K}^{+}$concentration to $50 \mathrm{~mm}$ or by adding veratrine $(33 \mu \mathrm{g} / \mathrm{ml})$ to the superfusion fluid ("stimulation condition"). The $\mathrm{Ca}^{2+}$ dependence of the $\mathrm{K}^{+}$-induced release was tested by substituting the superfusion fluid with a modified Earl's bicarbonate buffered salt solution containing $0.1 \mathrm{mM} \mathrm{Ca}^{2+}$ and $12 \mathrm{mM} \mathrm{Mg}^{2+}$. The superfusates were lyophilized, and the slices were collected from the chambers for protein determination.

\section{Preparation of $D A B T C$ derivatives}

4- $N, N$-Dimethylamino-azobenzene-4'-thiocarbamoyl (DABTC) derivatives of amino acids in superfusates were prepared by the method of 


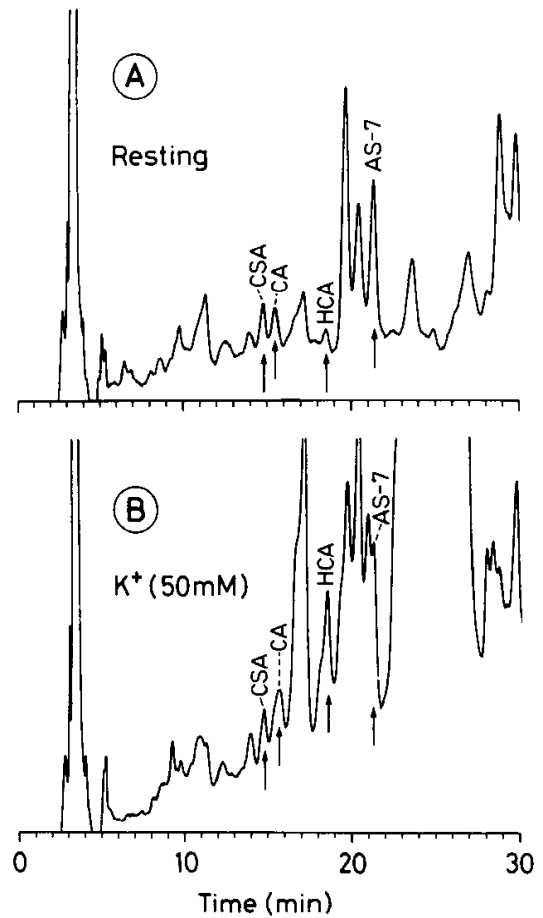

Figure 1. Analysis of the $\mathrm{K}^{+}$-induced release from basal ganglia slices in presence of $\mathrm{Ca}^{2+}$. $A$ and $B$, Chromatograms of DABTC derivatives in superfusates. Perfusion with Earl's bicarbonate buffer solution containing $2 \mathrm{mM} \mathrm{Ca}^{2+}$ and $1 \mathrm{mM} \mathrm{Mg}^{2+}$. $A$, Resting conditions $3.75 \mathrm{~mm}$ $\left.\mathbf{K}^{\prime}\right)$. $B$, Stimulation conditions (50 $\mathrm{mm} \mathbf{K}^{\prime}$ ). Chromatographic conditions were as described in the text. Solvent $A$ was $35 \mathrm{~mm}$ acetate buffer, pH 5.5; solvent B, acetonitrile. In this part of the chromatogram, an isocratic elution at $20 \%$ of solvent B was used. AS-7 was used as standard; in some cases, under stimulation conditions, its peak overlapped partially with that of other compounds; in such cases the integration was made disregarding the overlapping peak. Note the strong increase of $\mathrm{HCA}$, while CSA and CA remained unaffected.

Chang (1981) as modified by Do et al. (1986). The lyophilized residue was redissolved in $1 \mathrm{ml}$ water, and $300 \mu \mathrm{l}$ of AS-7 $(1 \mu \mathrm{g} / \mathrm{ml}$ in water) was added as internal standard as well as $1.5 \mathrm{ml}$ of DABITC solution $(0.3 \mathrm{mg} / \mathrm{ml}$ in pyridine, freshly prepared $)$. The mixture was heated at $70^{\circ} \mathrm{C}$ for $90 \mathrm{~min}$, and the excess of DABITC was extracted with heptaneethyl acetate $(2: 1, \mathrm{vol} / \mathrm{vol})$. The aqueous phase was evaporated to dryness and the residue redissolved in $1 \mathrm{ml} \mathrm{aq.} 50 \%$ (vol $/ \mathrm{vol})$ ethanol, filtered, and analyzed by HPLC.

\section{HPLC}

Analytical Hyperchrome HPLC columns, $250 \times 4.6 \mathrm{~mm}$ (Bischoff, Leonberg, FRG), packed with Spherisorb ODS II $5 \mu$ (Phase Sep, CT) were used in combination with a guard column. The HPLC system consisted of a Hewlett-Packard chromatograph (model 1090) combined with an autoinjector and a diode array spectrometer. The detection of DABTC derivatives of amino acids was performed at $455 \mathrm{~nm}$. The mobile phase consisted of $0.035 \mathrm{M}$ acetate buffer $(\mathrm{pH} 5.5)$ and acetonitrile. The flow rate was $1 \mathrm{ml} / \mathrm{min}$, and a linear step gradient from 20 to $80 \%$ acetonitrile was run at room temperature for 60 or $80 \mathrm{~min}$. A Spectra Physics integrator (model 4270) was used to evaluate the peak areas using the internal standard AS-7 for calibration.

\section{Intracellular recordings and iontophoresis}

The surgical methods and the procedures for intracellular recording in the caudate with simultaneous microiontophoretic application of drugs during stimulation of the corticocaudate pathway have previously been described in detail (Herrling et al., 1983). Briefly, mongrel cats of either sex, $3.0-4.5 \mathrm{~kg}$, were anesthetized for surgery by intravenous injection of an ultra-short-acting barbiturate (Brietal, Lilly, Giessen, FRG) and the saphenous vein and femoral artery cannulated for drug injections and blood pressure measurements, respectively. Tracheotomy for ar-

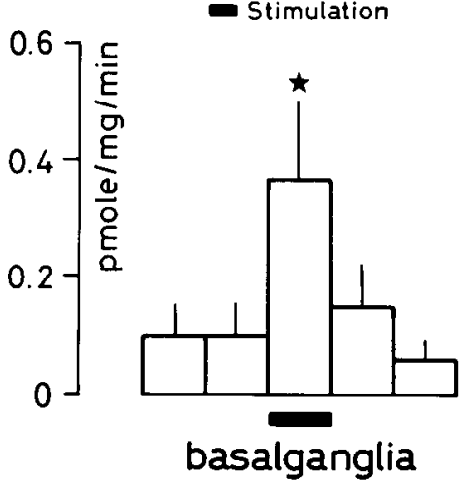

Figure 2. Time course of $\mathrm{K}^{+}$depolarization-induced release of $\mathrm{HCA}$ from striatal slices. Five consecutive $5 \mathrm{~min}$ fractions were analyzed and expressed in $\mathrm{pmol} / \mathrm{mg}$ protein $/ \mathrm{min}$; the third fraction corresponded to the 4 min stimulation period in $50 \mathrm{mM} \mathrm{K} \mathrm{K}^{+}$. Column heights represent the mean concentrations ( \pm SEM) of 5 independent experiments; about $1 \mathrm{gm}$ striatal tissue (wet wt) from 4 rats was used in each experiment. Asterisks denote significant differences between efflux during stimulation or resting conditions: ${ }^{*}, p<0.05$, unpaired Student's $t$ test.

tificial respiration and a bilateral pneumothorax and opening of the cisterna magna to reduce cardiovascular and respiratory pulsations were performed. The skull was exposed and windows (ca. $1.5 \times 1.5 \mathrm{~cm}$ ) opened vertically above the lateral ventricles. The cortical tissue overlying the caudate was removed by suction until the lateral ventricles were reached. Stimulation electrodes were implanted through the opened frontal sinuses in the anterior sigmoid gyrus bilaterally. The positions of the recording electrodes were verified histologically.

At the end of surgery, anesthesia was switched to $0.5-1.5 \%$ halothane (Halothan, Hoechst, Frankfurt, FRG) in pure oxygen. The body temperature was kept at $37-38^{\circ} \mathrm{C}$ and end-tidal $\mathrm{CO}_{2}$ in the tracheal cannula at $3.6-4.4 \%$. Cell recordings were included in the present study only if mean blood pressure was above $80 \mathrm{~mm} \mathrm{Hg}$.

One channel of the iontophoretic and recording electrode assemblies was filled with a physiological $\mathrm{NaCl}$ solution for occasional balance controls and one channel with the same $\mathrm{NaCl}$ solution but at pH 9.8 as an approximate $\mathrm{pH}$ and current control. The intertip distance between recording and iontophoretic electrodes was about $50 \mu \mathrm{m}$.

Recording electrodes were filled with $1.6 \mathrm{M}$ potassium citrate adjusted to $\mathrm{pH} 7.2$ with citric acid, and they had a resistance of $80-150 \mathrm{M} \Omega$ measured in the cerebrospinal fluid just before penetration of the tissue. The signals from the recording electrode were amplified and displayed on commercially available equipment and were stored on FM audiotape for later analysis. Data were analyzed by digitizing the membrane potential recordings (program BASAL, written by $P$. Linscheid) during the period around cortical stimulation, averaging consecutive sequences to allow detection of drug-induced changes of the evoked responses. Statistical analysis was achieved by performing a point-by-point Student's $t$ test between the averages of control and test responses.

\section{Frog hemisected spinal cord}

A detailed account of the procedures was published previously (Herrling, 1985). In short, hemisected frog (Rana temporaria) spinal cords were transferred to a cooled Perspex chamber and perfused with a Ringer's solution $\left(\mathrm{NaCl}, 111 \mathrm{~mm} ; \mathrm{KCl}, 2 \mathrm{~mm} ; \mathrm{CaCl}_{2}, 2 \mathrm{~mm}\right.$; glucose, $10 \mathrm{~mm}$; Tris, $10 \mathrm{~mm}, \mathrm{pH} 7.2$, at $10-12^{\circ} \mathrm{C}$. $\mathrm{DC}$ recordings were made between the tips of the ventral roots and the hemisected body of the spinal cord containing the motoneuron somata. Agonists were applied for $1 \mathrm{~min}$, antagonists for as long as it took to construct dose-rcsponsc curves with the agonists. The first agonist dose was applied at least $30 \mathrm{~min}$ after the beginning of superfusion with the antagonist. The size of the agonistinduced responses was determined by calculating the area under the drug-elicited depolarizations. Antagonism was evaluated by calculating $\mathrm{p} A_{2}$ values:

$$
\mathrm{p} A_{2}=-\log [I]+\log \left[\left(A_{50} / B_{s 0}\right)-1\right]
$$

where $[I]$ is the concentration of the antagonist, $A_{50}$ the half-maximal effect of the agonist in presence of the antagonist, and $B_{s 0}$ the halfmaximal effect of the agonist alone (Wenke, 1971). As an alternative 
Table 1. Rate of in vitro release of HCA, Asp, and Glu under resting and stimulation conditions in various rat brain regions

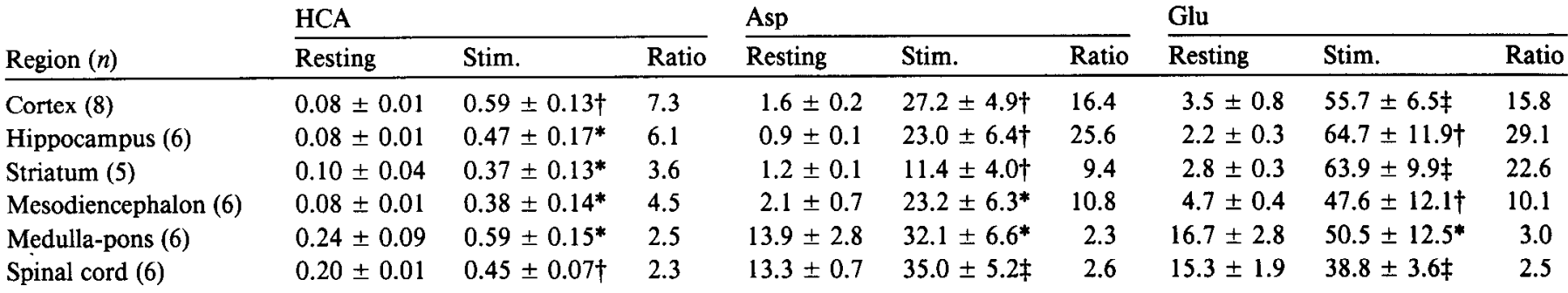

Mean value (in pmol/mg protein/min \pm SEM) of $n$ independent experiments. For each compound, the ratio of the stimulation (stim.) over resting values is shown in the third column, giving an estimate of the relative release. Significance determined with Student's $t$ test of the difference between stimulation and resting values: ${ }^{*} p<$ $0.05, \dagger p<0.01, \ddagger p<0.001$. The different parts were obtained by microscopic dissection of ice-cooled brain as follows: cerebellum (section of the peduncles),

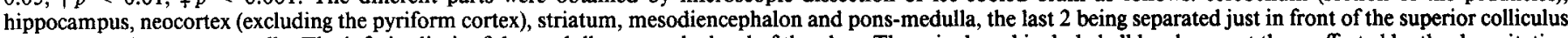

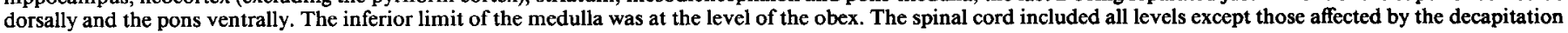
and was freed of white matter as much as possible.

method, Schild plots were calculated to determine $\mathrm{p} A_{2}$ values graphically (Arunlakshana and Schild, 1959; Kenakin, 1982; Wenke, 1971).

\section{Results}

\section{Release}

With rat striatal slices superfused under resting or depolarizing conditions, the HPLC analysis of the superfusates gave the chromatograms shown in Figure 1. Compared to the other sulfurcontaining amino acids, HCA showed the largest increase during stimulation induced by $50 \mathrm{mM} \mathrm{K}^{+}$, while CA and CSA remained unaffected. The efflux of $\mathrm{HCA}$ increased from $0.10 \mathrm{pmol} / \mathrm{mg}$ protein $/ \mathrm{min}$ under resting conditions to $0.36 \mathrm{pmol} / \mathrm{mg}$ protein/ min under stimulation conditions (Fig. 2), for a relative release ratio of 3.6. A ratio significantly greater than 1 was considered as indicative of stimulation-induced release. This HCA release, as well as that of Glu and Asp, was $\mathrm{Ca}^{2+}$-dependent: In presence of $0.1 \mathrm{mM} \mathrm{Ca}^{2+}$ and $12 \mathrm{mM} \mathrm{Mg}^{2+}$, the $\mathrm{HCA}$ resting efflux was below sensitivity of the method and $\mathrm{K}^{+}$-induced depolarization remained without observable effect. As with Glu and Asp, the $\mathrm{Ca}^{2+}$-dependent release of HCA occurred in striatal slices, as well as in other regions (Table 1).

When $33 \mu \mathrm{g} / \mathrm{ml}$ veratrine was applied, a similar release pattern was observed: The resting efflux of HCA from striatal slices was below the sensitivity of the method, while under stimulation it amounted to $0.95 \mathrm{pmol} / \mathrm{mg}$ protein $/ \mathrm{min}$. CA efflux was also increased after veratrine, an observation contrasting with the results obtained with $\mathrm{K}^{+}$depolarizations. In the veratrine experiments, generally, the increase of amino acid efflux was seen not only in the fraction containing veratrine, but also in the following one(s).

Table 2. Comparison of the firing patterns elicited by different agonists in the same cells

\begin{tabular}{|c|c|c|c|c|c|c|c|}
\hline Cell & NMDA & QUIS & (L)-HCA & Cell & NMDA & QUIS & $\begin{array}{l}\text { (L)- } \\
\text { HCA }\end{array}$ \\
\hline $21 \mathrm{D} 1$ & & I & II & 31D1 & II & & II \\
\hline $21 \mathrm{D} 2$ & & I & II & 32D1 & II & & II \\
\hline $21 \mathrm{D} 3$ & & I & II & 32D2 & II & & II \\
\hline $21 \mathrm{D} 4$ & & I & II & $32 \mathrm{D} 3$ & II & & II \\
\hline $21 \mathrm{D} 5$ & & I & II & $72 \mathrm{~T} 1$ & II & I & II \\
\hline 21D6 & & I & I & $72 \mathrm{~T} 2$ & II & I & II \\
\hline 22D1 & & & II & $73 \mathrm{~T} 1$ & II & I & I \\
\hline $22 \mathrm{D} 2$ & & & II & $73 \mathrm{~T} 2$ & II & I & II \\
\hline 24D1 & & I & II & $73 \mathrm{~T} 3$ & & I & II \\
\hline $24 \mathrm{D} 2$ & II & I & II & $74 \mathrm{~T} 1$ & & I & I \\
\hline 24D3 & & I & II & $74 \mathrm{~T} 3$ & & I & I \\
\hline 25D1 & & & II & $74 \mathrm{~T} 4$ & & I & I \\
\hline 25D2 & II & & II & $74 \mathrm{~T} 5$ & & I & II \\
\hline 27D2 & II & & I & $74 \mathrm{~T} 6$ & & I & II \\
\hline $28 \mathrm{D} 3$ & II & & II & $75 \mathrm{~T} 1$ & & I & II \\
\hline 29D1 & & & II & $84 \mathrm{~T} 1$ & II & & II \\
\hline 29D2 & II & I & II & $05 \mathrm{~J} 1$ & II & & II \\
\hline 29D3 & II & & II & $06 \mathrm{~J} 1$ & II & & II \\
\hline $30 \mathrm{D} 1$ & II & & II & 33D1 & II & & II \\
\hline \multirow[t]{2}{*}{$30 \mathrm{D} 2$} & II & & II & 33D2 & II & & II \\
\hline & & & & 33D3 & II & & II \\
\hline
\end{tabular}

I: regular firing pattern, defined as type $I$ if it was similar to the pattern shown in Figure $3 c$.

II: burstlike firing pattern, defined as type II if it was similar to the pattern shown in Figure $3, a$ or $b$. 


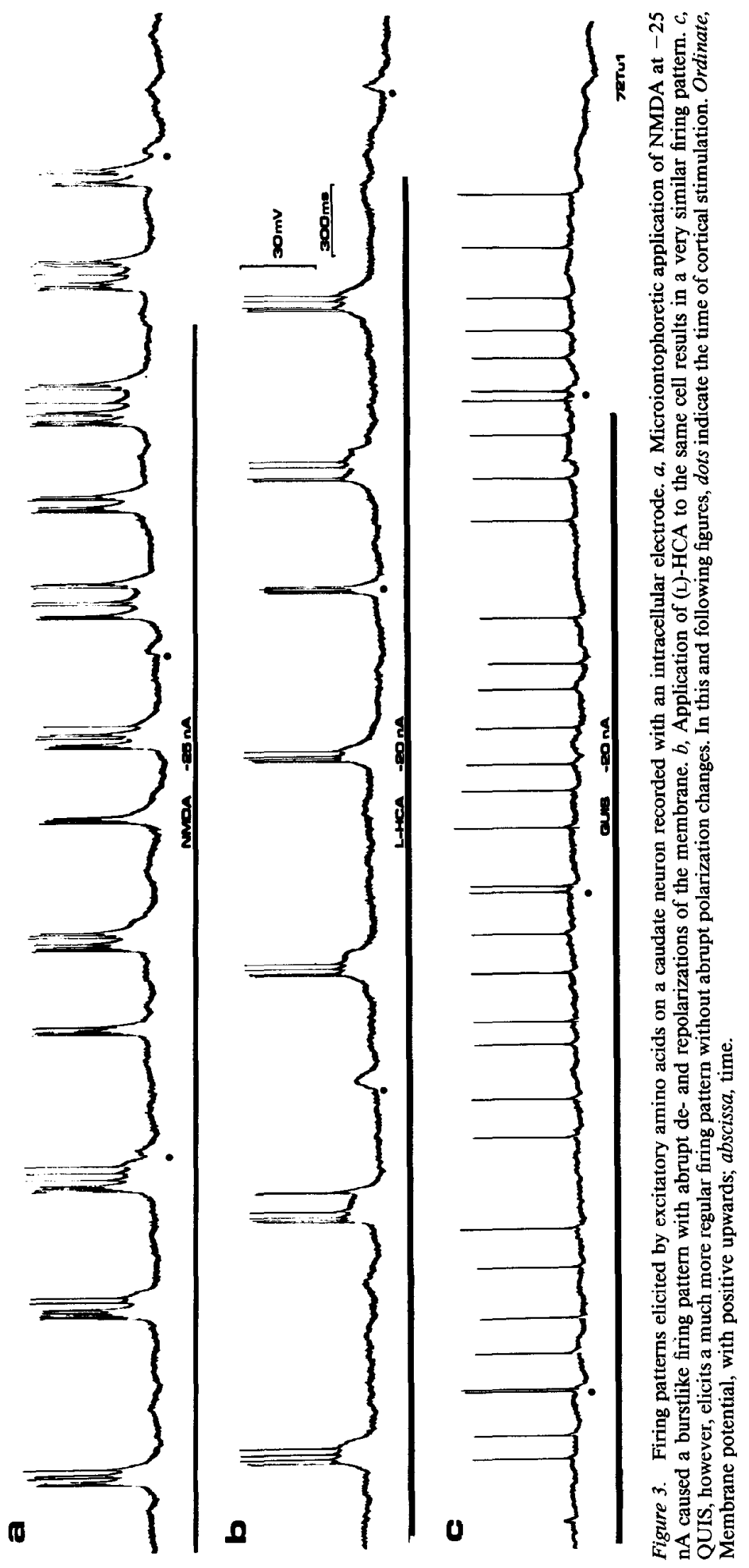


Table 3. Comparison of the durations of NMDA- and (L)-HCAinduced abrupt depolarizations

\begin{tabular}{|c|c|c|c|c|c|}
\hline \multirow[b]{2}{*}{ Cell } & \multicolumn{2}{|l|}{ NMDA } & \multicolumn{2}{|l|}{ (L)-HCA } & \multirow[b]{2}{*}{$t$ Test } \\
\hline & $\begin{array}{l}\begin{array}{l}\text { Duration } \\
\text { (msec) }\end{array} \\
\end{array}$ & $n$ & $\begin{array}{l}\text { Duration } \\
\text { (msec) }\end{array}$ & $n$ & \\
\hline $72 \mathrm{~T} 1$ & $83 \pm 28$ & 33 & $99 \pm 27$ & 29 & $p>0.05$ \\
\hline $72 \mathrm{~T} 2$ & $42 \pm 19$ & 18 & $35 \pm 8$ & 22 & $p>0.05$ \\
\hline $73 \mathrm{~T} 1$ & $96 \pm 41$ & 15 & Type I & & - \\
\hline $73 \mathrm{~T} 2$ & $118 \pm 44$ & 13 & $93 \pm 34$ & 18 & $p>0.05$ \\
\hline $73 \mathrm{~T} 3$ & $239 \pm 60$ & 14 & $91 \pm 25$ & 15 & $p<0.001$ \\
\hline $84 \mathrm{Tl}$ & $584 \pm 295$ & 10 & $112 \pm 28$ & 18 & $p<0.001$ \\
\hline
\end{tabular}

Mean durations $( \pm$ SD) at half-maximal amplitude are given. Type I, regular firing pattern, no abrupt depolarizations. $n$, number of measured abrupt depolarizations.

\section{Electrophysiology}

\section{Cell types and characteristics}

Results were obtained from 41 neurons in the caudate nuclei of 18 cats at depths ranging from 500 to $4000 \mu \mathrm{m}$ below the dorsal surface at AP +16.5 to +17.5 (Berman and Jones, 1982). These neurons were presumed to be of the medium spiny lype, since other investigators who used HRP-filled intracellular electrodes in the cat (Kocsis and Kitai, 1977) and rat (Bishop et al., 1982) reported that the great majority of stained cells in the caudate were of this type.

Intracellular recordings lasted $10-40 \mathrm{~min}$. In most, there were no spontaneous action potentials. These could be elicited by intracellular electrical stimulation, iontophoretic application of drugs, or stimulation of excitatory afferent pathways. The resting potential of cells was estimated from the potential drop at the end of the intracellular recordings, the mean $( \pm \mathrm{SD})$ being $54 \pm$ $100 \mathrm{mV}(n=19)$. Action potential amplitudes ranged from 30 to $70 \mathrm{mV}(41 \pm 9 \mathrm{mV})$, with durations of $0.5-1.5 \mathrm{msec}$ at halfmaximal amplitude.

To determine if intracellularly measured cortically evoked synaptic potentials were contaminated by field potentials, the corticocaudate pathway was stimulated when the tip of the recording electrode was placed extracellularly. Under these conditions, no evidence of field potentials was observed.

\section{Firing pattern}

(L)-HCA applied to caudate neurons elicited a pronounced burstlike firing pattern in 36 of 41 cells (Table 2, Fig. 3). It was very similar to the type II pattern seen with NMDA in an earlier study (Herrling et al., 1983). In the 5 remaining cells (L)-HCA evokcd a regular firing pattern. Excitations elicited on the same neuron by QUIS, NMDA, and (L)-HCA were compared in 7 cases: QUIS elicited the regular type I pattern, while both NMDA and (L)-HCA applications resulted in irregular firing patterns (Fig. 3). In 6 other cells in which the actions of NMDA and (L)HCA were compared, firing patterns were examined in more detail by measuring the duration of the abrupt depolarizations at half-maximal amplitude. These depolarizations induced by (L)-HCA were either of equal duration or shorter than those elicited by NMDA on the same cells, never significantly longer (Table 3). To exclude the possibility of an iontophoretic channel spillover effect at the tips, many of the recordings (18 of 41) were done with electrode assemblies containing no NMDA. Under these conditions, (L)-HCA also evoked a burstlike firing pattern (14 of 18).

\section{Sensitivity to a selective NMDA antagonist}

Cat caudate. In order to test for the occurrence of an interaction of (L)-HCA with NMDA receptors, experiments were performed using (D)- or (D,L)-AP-7, selective and potent NMDA antago-
Table 4. Inhibition of excitatory amino acid-induced depolarizations in the frog hemisected spinal cord in vitro

\begin{tabular}{lcc}
$\begin{array}{l}\text { Agonist } \\
\text { (DRC) }\end{array}$ & $\begin{array}{l}\text { (D,L)-AP-7 } \\
\text { concentration } \\
(\mu \mathrm{M})\end{array}$ & $\mathrm{p} A_{2}$ value \\
\hline Quisqualate & 50 & 3.5 \\
& 200 & $<2.0$ \\
& 200 & $<2.0$ \\
(L)-HCA & 10 & 5.1 \\
& 20 & 5.0 \\
& 50 & 4.9 \\
& 100 & 5.1
\end{tabular}

(L)-HCA ${ }^{a}$

+ kynurenic acid, $100 \mu \mathrm{M}$

10

4.3

${ }^{a}$ In this experiment, the spinal cord was continuously perfused with $10 \mu \mathrm{M}(\mathrm{D}, \mathrm{L})-$ AP-7 and the remaining depolarizations antagonized by $100 \mu \mathrm{M}$ kynurenic acid. DRC, Dose-response curves (for typical example see Fig. $4 d$ ).

nists (Evans et al., 1982; Perkins et al., 1982). In 15 cells, (L)HCA-induced excitations were easily inhibited by simultaneous application of AP-7. In contrast, QUIS-induced excitation of the same cell was much less affected, if at all (Fig. 4,a-c). NMDAand (L)-HCA-induced excitations were about equally inhibited.

Frog hemisected spinal cord. A more quantitative evaluation of the interactions of (L)-HCA with excitatory amino acid receptors was attempted in vitro using the amphibian hemisected spinal cord assay. Dose-response curves were constructed in presence and absence of antagonists with QUIS and (L)-HCA. QUIS-induced depolarizations were practically unaffected by AP-7, but (L)-HCA dose-response curves showed a distinct displacement to the right (Fig. 4d, Table 4). As an alternative method for evaluating the interaction of (L)-HCA with NMDA receptors, we constructed a Schild plot using the same data used for Table 4 (Arunlakshana and Schild, 1959). This resulted in a straight line $(Y=4.53+0.89 X)$, with a regression coefficient of 0.965 ; the $\mathrm{p} A_{2}$ value determined graphically with this method was 5.2. To evaluate the interaction of (L)-HCA with non-NMDA receptors, we compared the dose-response curve obtained with (L)-HCA in presence of $10 \mu \mathrm{M} \mathrm{AP-7} \mathrm{with} \mathrm{that} \mathrm{obtained} \mathrm{in} \mathrm{pres-}$ ence of both AP-7 and $100 \mu \mathrm{M}$ kynurenic acid, a broad-spectrum competitive antagonist of excitatory amino acids (Herrling, 1985; Perkins and Stone, 1982). This result indicates that there is a component remaining in presence of AP-7 that can be antagonized by kynurenic acid (Table 4).

\section{Interaction with cortically evoked synaptic potentials}

(L)-HCA was applied to 9 cells during stimulation of the corticocaudate pathway at frequencies from 2 to $4 \mathrm{~Hz}$. The resulting EPSPs were digitized, averaged, and compared to EPSPs evoked in the same cells in the absence of (L)-HCA and in presence of QUIS or (L)-CSA. In 7 cells, the EPSP amplitude and/or durations were greater during (L)-HCA-induced depolarizations compared to predrug controls, and they developed several action potentials. In 5 cases, (L)-HCA and QUIS were applied to the same cells. The iontophoretic currents for the application of QUIS were adjusted to give the same depolarization levels as those achieved during (L)-HCA application. Under these conditions EPSP durations and/or amplitudes, as well as the number of evoked action potentials, were always distinctly greater under the influence of (r)-HCA than of QUIS or CSA (Fig. 5).

\section{Discussion}

HCA was among the first excitatory amino acids investigated by Curtis and coworkers in both amphibians (Curtis et al., 1961) 

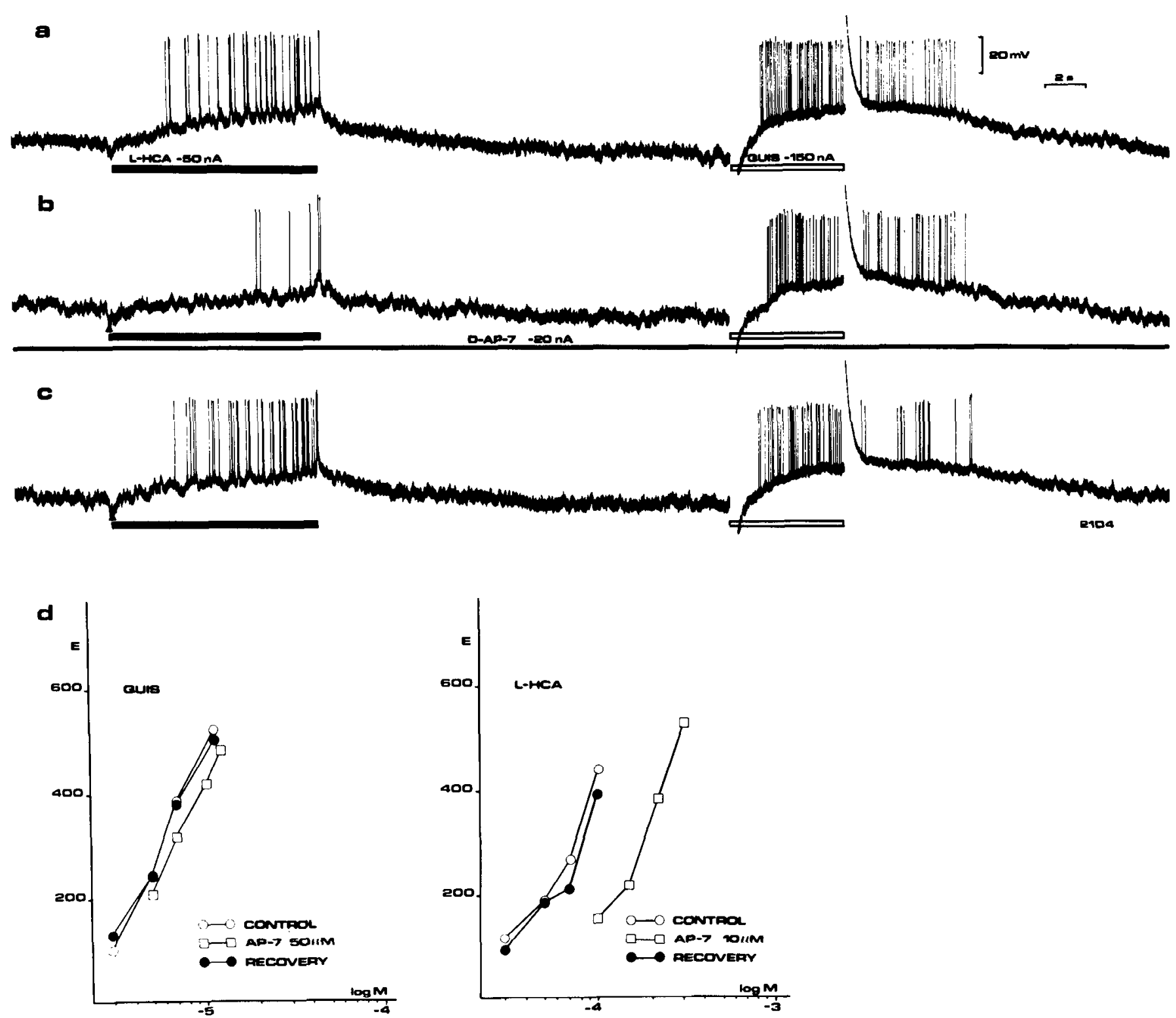

Figure 4. Selective inhibition of the excitatory effects of (L)-HCA by AP-7 in the cat caudate in situ and in the frog hemisected spinal cord in vitro. $a$, Microiontophoretic application of (L)-HCA and QUIS to a caudate neuron. $b$, Selective inhibition of the effects of (L)-HCA by (D)-AP-7 in the same neuron. Arrowhead at $40 \mathrm{sec}$ after application of AP-7. c, Full recovery after the end of application of the antagonist. Arrowhead at 60 sec after end of AP-7 application. The gaps in the recordings at the beginning of QUIS applications are due to a particularly strong coupling artifact between the iontophoretic barrel containing QUIS and the recording electrode (QUIS barrel resistance was $650 \mathrm{M} \Omega$ and recording electrode resistance $400 \mathrm{M} \Omega$ in the tissue, rather higher than usual in these recordings). $d$, Left, Effects of different concentrations of QUIS in the absence and presence of $50 \mu \mathrm{M}(\mathrm{D}, \mathrm{L})-\mathrm{AP}-7$ in the frog spinal cord. There is only a very weak inhibition. Right, Effects of different concentrations of (L)-HCA in the absence and presence of $10 \mu \mathrm{M}(\mathrm{D}, \mathrm{L})-\mathrm{AP}-7$. There is a distinct parallel shift of the dose-response curve to the right in presence of the antagonist, and a full recovery after washout. $E$, Area under the curve for the first $5 \mathrm{~min}$ after a $1 \mathrm{~min}$ application of the agonists. Units are arbitrary.

and mammalian (Curtis and Watkins, 1963) tissue. The (D)isomer was found to be one of the most potent excitatory agents, similar to NMDA. The (L)-isomer appeared to be about 5 times weaker (Curtis and Watkins, 1963); however, this might have been due to a stereoselective inactivation system for (L)-HCA (Cox et al., 1977).

\section{Release}

Despite the fact that HCA has been included in numerous studies, its depolarization-induced release as an endogenous compound from central neural tissue is here reported for the first time. The use of the DABITC precolumn derivatization HPLC method enabled us to detect HCA in biological material at the picomole level simultaneously with other polar sulfur-containing amino acids. HCA was also present in trichloroacetic acid extracts of rat brain tissue (data not shown). However, a prepurification would be required for a quantitative determination, as its peak was partly masked by high concentrations of other substances. A striking increase of HCA release compared to resting levels was found in striatum, as well as in most other brain regions. A neuronal, possibly synaptic origin of the HCA release is likely as it is $\mathrm{Ca}^{2+}$-dependent. The prolonged effect of veratrine observed is probably related to a slow diffusion process of this agent. These observations are consistent with the concept that HCA is a neurotransmitter or a metabolite of a transmitter in the rat CNS. The relatively small amount of HCA released 
$\approx$
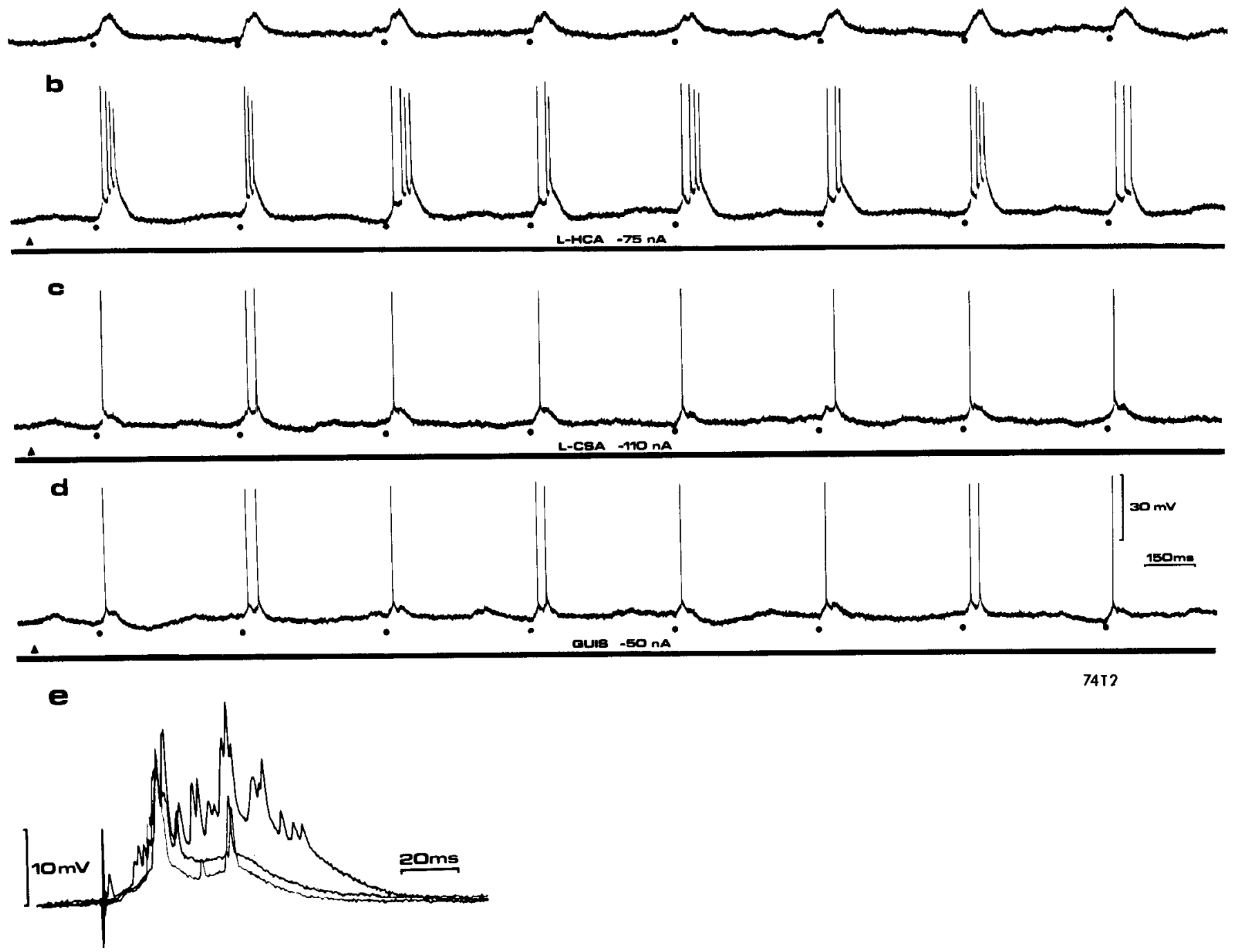

74T2

Figure 5. Interactions of excitatory amino acids with cortically evoked EPSPs in a caudate neuron. $a$, Control. The corticocaudate pathway was stimulated in the absence of iontophoretically applied drugs. Stimulation frequency was $2.5 \mathrm{~Hz}$, intensity $3 \mathrm{~mA}$, and duration $300 \mu$ sec. The stimulation parameters were identical in $a-d . b$, Cortically evoked EPSPs display a clearly larger amplitude and duration during the application of (L)-HCA, and there are several evoked action potentials. The membrane was depolarized by $12 \mathrm{mV}$ with respect to control. Arrowhead at 35 sec after the beginning of agonist application. $c$, Same experiment as in $b$, but (L)-CSA was agonist. The membrane potential was also depolarized by $12 \mathrm{mV}$, but EPSP amplitude, duration, and number of evoked action potentials were distinctly less than with (L)-HCA. Arrowhead at 27 sec after beginning of agonist application. $d$, As in $c$, but with QUIS as agonist. The depolarization was again $12 \mathrm{mV}$ and the effects on EPSPs as with (L)CSA. Arrowhead at $17 \mathrm{sec}$ after beginning of agonist application. $e$, Superimposition of averaged cortically evoked EPSPs in the same cell with the same agonists. Upper trace, average of 15 EPSPs during (L)-HCA application; middle trace, average of 20 EPSPs during (L)-CSA; lower trace, average of 20 EPSPs during QUIS. The differences between the upper trace and both lower ones are statistically significant.

might be explained by assuming that a limited number of synaptic compartments are responsible for the release.

\section{Electrophysiology}

\section{Pharmacology}

Although our HPLC method does not allow an enantiomeric analysis of the released HCA, we chose (L)-HCA for our electrophysiological experiments under the assumption that it is the endogenously occurring isomer. Both our in vitro and in situ results indicate a preferential interaction of (L)-HCA with NMDA receptors as characterized by Watkins and Evans (1981):

1. The firing and depolarization pattern elicited by $(\mathrm{L})-\mathrm{HCA}$ in most cells is very similar to the pattern elicited by NMDA but differs clearly from QUIS (Herrling et al., 1983) or kainate (Herrling, 1985) induced firing patterns.

2. Excitations induced by (L)-HCA in caudate neurons were inhibited by (D)- or (D,L)-AP-7, a selective NMDA antagonist (Evans et al., 1982; Perkins et al., 1982). QUIS-elicited excitations on the same neurons were only weakly affected, if at all, by this antagonist.

3. In the hemisected frog spinal cord, (I.)-HCA-induced depolarizations were also clearly inhibited by (D,L)-AP-7, while QUIS depolarizations were not. However, the $\mathrm{p} A_{2}$ value obtained with AP-7 against NMDA was larger, 5.5 (Herrling, 1985) than the $\mathrm{p} \mathrm{A}_{2}$ value of around 5.0 obtained here against (L)-HCA. 
All tests usually believed to indicate competitive antagonism with one receptor site-i.e., same $\mathrm{p} A_{2}$ values at different antagonist concentrations or a straight-line, $45^{\circ}$-slope Schild plotwere positive for the antagonism of (L)-HCA by AP-7. There is, however, a discrepancy between the values obtained with AP-7 on NMDA- and on (L)-HCA-induced depolarizations. This discrepancy could be due to an additional interation of (L)-HCA with QUIS or kainate receptors. This interpretation is supported by the $\mathrm{p} A_{2}$ value of 4.3 obtained if (L)-HCA depolarizations are antagonized by the broad-spectrum antagonist kynurenic acid (Perkins and Stone, 1982) and if the NMDA component of (L)HCA effects is inhibited by constant perfusion of $10 \mu \mathrm{M} \mathrm{AP-7}$ and by kynurenic acid itself, which has a $\mathrm{p} A_{2}$ value of 4.8 against NMDA (Herrling, 1985). The value of 4.3 obtained during NMDA inhibition is very similar to the $\mathrm{p} A_{2}$ value of around 4.0 obtained previously in experiments in which QUIS-induced depolarizations were antagonized by kynurenic acid (Herrling, 1985). A p $A_{2}$ of 4.0 was also found when kynurenate was used to antagonize kainate-induced sodium efflux in striatal slices $(P$. Frey, personal communication). While the interpretation of $\mathrm{p} A_{2}$ values obtained with an agonist that interacts with more than one receptor is not quite certain, taken together, our in vitro results indicate that (L)-HCA interacts with NMDA receptors, but that an additional non-NMDA component is probably present. Our data on caudate neurons very strongly suggest that, at least in this structure of the cat brain, the effects resulting from interactions with the NMDA receptor clearly predominate, since QUIS-like firing and depolarization patterns occur rarely, while NMDA patterns are observed on most cells. Furthermore, this latter pattern can be completely abolished by AP-7, and no QUIS-like pattern persists in presence of this antagonist. Such an interpretation would be consistent with those of a previous study in the immature rat spinal cord (Mewett et al., 1983), where (L)-HCA showed greater sensitivity to NMDA antagonists compared with Glu, even though in that study only approximate ratings were given and affinities were not reported. Sensitivity of (L)-HCA to the NMDA antagonist $(D, L)$-alpha-aminoadipic acid was also shown in the cat spinal cord in situ during extracellular recording and iontophoresis (McLennan and Lodge, 1979). Only in one study was (L)-HCA grouped with QUIS agonists (Lambert et al., 1981). This characterization was based on observations of the effects of excitatory amino acid agonists applied by iontophoresis on the time course of firing and on membrane conductance of motoneurons recorded in situ. The reasons for this diverging conclusion are not quite clear, but Lambert and colleagues did not report on the type of firing and depolarization pattern evoked by (L)-HCA, and no selective antagonists were used.

\section{Effects on synaptic potentials}

Because of reports demonstrating that NMDA and (L)-HCA cause a region of "negative slope conductance" in the currentvoltage relationship in cultured central neurons (Mayer and Westbrook, 1984, 1985; Nowak et al., 1984), the last authors suggested that NMDA agonists might potentiate EPSPs at low concentrations. In a study parallel to the present one (Herrling and Turski, unpublished observations), this potentiation was found to occur during NMDA iontophoresis in cat caudate neurons. When the above results indicated that (L)-HCA interacted with NMDA receptors, effects of this agonist on cortically evoked EPSPs were studied. They showed that (L)-HCA is also capable of potentiating these synaptic potentials to a clearly greater extent than QUIS or (L)-CSA applied to the same cells. These observations with (L)-HC.A are consistent with findings of Engberg et al. (1979), who observed a similar potentiation of EPSPs with (D,L)-HCA in cat motoneurons recorded in situ.

In conclusion, the present results indicate that $(\mathrm{L})-\mathrm{HCA}$ is a NMDA-preferring mixed agonist of excitatory amino acid re- ceptors and that this endogenous compound is capable of potentiating cortically evoked EPSPs in cat caudate neurons. Our findings support the hypothesis that one function of released endogenous excitatory amino acids interacting with NMDA receptors is to achieve an increase in the gain of incoming EPSPs. As our results indicate that HCA is released from striatal tissue in a calcium-dependent manner, this compound might be proposed as an endogenous agonist of NMDA receptors.

\section{References}

Arunlakshana, O., and H. O. Schild (1959) Some quantitative uses of drug antagonists. Br. J. Pharmacol. 14: 48-58.

Berman, A. L., and E. G. Jones (1982) The Thalamus and Basal Telencephalon of the Cat, University of Wisconsin Press, Madison.

Bishop, G. A., H. T. Chang, and S. T. Kitai (1982) Morphological and physiological properties of neostriatal neurons: An intracellular horseradish peroxidase study in the rat. Neuroscience $7: 179-191$.

Chang, J.-Y. (1981) Isolation and characterization of polypeptides at the picomole level. Biochem. J. 199: 537-545.

Cox, D. W. G., M. H. Headley, and J. C. Watkins (1977) Actions of $\mathrm{L}$ - and $\mathrm{D}$-homocysteate in rat CNS: A correlation betwecn low-affinity uptake and the time courses of excitation by microelectrophoretically applied L-glutamate analogues. J. Neurochem. 29: 579-588.

Curtis, D. R., and J. C. Watkins (1963) Acidic amino acids with strong excitatory actions on mammalian neurones. J. Physiol. (Lond.) 166: $1-14$.

Curtis, D. R., J. W. Phillis, and J. C. Watkins (1961) Actions of aminoacids on isolated hemisected spinal cord of the toad. Br. J. Pharmacol. 16: 262-283.

Do, K. Q., M. Mattenberger, P. Streit, and M. Cuenod (1986) In vitro release of endogenous excitatory sulphur containing amino acids from various rat brain regions. J. Neurochem. 46: 779-786.

Engberg, I., J. A. Flatman, and J. D. C. Lambert (1979) The actions of excitatory amino acids on motoneurones in the feline spinal cord. J. Physiol. (Lond.) 288: 227-261.

Evans, R. H., A. A. Francis, A. W. Jones, D. A. S. Smith, and J. C. Watkins (1982) The effects of a series of omega-phosphonic alphacarboxylic amino acids on electrically evoked and excitant amino acid-induced responses in the isolated spinal cord preparation. Br. J. Pharmacol. 75: 65-75.

Herrling, P. L. (1985) Pharmacology of the corticocaudate excitatory postsynaptic potential in the cat: Evidence for its mediation by quisqualate- or kainate-receptors. Neuroscience 14: 417-426.

Herrling, P. L., R. Morris, and T. E. Salt (1983) Effects of excitatory amino acids and their antagonists on membrane and action potentials of cat caudate neurones. J. Physiol. (Lond.) 339: 207-222.

Kenakin, T. P. (1982) The Schild regression in the process of receptor classification. Can. J. Physiol. Pharmacol. 60: 249-263.

Kocsis, J. D., and S. T. Kitai (1977) Dual excitatory inputs to caudate spiny neurons from substantia nigra stimulation. Brain Res. 138:271283.

Lambert, J. D. C., J. A. Flatman, and I. Engberg (1981) Actions of excitatory amino acids on membrane conductance and potential in motoneurones. In Glutamate as a Neurotransmitter, G. DiChiara and G. L. Gessa, eds., pp. 205-216, Kaven, New York.

Mayer, M. L., and G. L. Westbrook (1984) Mixed-agonist action of excitatory amino acids on mouse spinal cord neurones under voltage clamp. J. Physiol. (Lond.) 354: 29-53.

Mayer, M. L., and G. L. Westbrook (1985) The action of N-methylD-aspartic acid on mouse spinal neurones in culture. J. Physiol. (Lond.) 361: 65-90.

McLennan, H., and D. Lodge (1979) The antagonism of amino acidinduced excitation of spinal neurones in the cat. Brain Res. 169: 8390.

Mewett, K. N., D. J. Oakes, H. J. Olverman, D. A. S. Smith, and J. Watkins (1983) Pharmacology of the excitatory actions of sulphonic and sulphinic amino acids. In CNS Receptors-From Molecular Pharmacology to Behavior, P. Mandel and F. V. DeFeudis, eds., pp. 163-174, Raven, New York.

Nowak, L., P. Bregestovski, P. Ascher, A. Herbet, and A. Prochiantz (1984) Magnesium gates glutamate-activated channels in mouse central neurones. Nature 307: 462-465.

Perkins, M. N., and T. W. Stone (1982) An iontophoretic investigation 
of the actions of convulsant kynurenines and their interaction with the endogenous excitant quinolinic acid. Brain Res. 247: 184-187.

Perkins, M. N., J. F. Collins, and T. W. Stone (1982) Isomeres of 2-amino-7-phosphonoheptanoic acid as antagonists of neural excitants. Neurosci. Lett. 32: 65-68.
Watkins, J. C., and R. H. Evans (1981) Excitatory amino acid transmitters. Annu. Rev. Pharmacol. 21: 165-204.

Wenke, M. (1971) Drug-receptor interactions. In Fundamentals of Biochemical Pharmacology, Z. M. Bacq, ed., pp. 367-410, Pergamon, New York. 